\title{
In situ alloying of aluminium-based alloys by (multi-)wire-arc additive manufacturing
}

\author{
Thomas Klein*, Alois Birgmann and Martin Schnall \\ LKR Light Metals Technologies Ranshofen, Austrian Institute of Technology, 5282 Ranshofen, Austria
}

\begin{abstract}
Wire-arc additive manufacturing (WAAM) has received considerable attention in the past years due to advantages in terms of deposition rate, design freedom, buy-to-fly ratio and economic factors. This process can generally be conducted using conventional or near-conventional welding equipment to fabricate intricate but relatively large-scale structures. The present contribution explores options to utilize this novel process not only for manufacturing of particular aluminium structures, but to create the actual alloy composition during processing. Thereby, the possibilities of dual-wire techniques based on cold metal transfer (CMT) to create alloys in the welding process in situ is investigated. For this purpose, a modified CMT twin welding system is used with standard wires differing significantly in their alloying content. The characterization of the chemical compositions at different specimen positions suggests good chemical homogeneity after initial process optimization steps. The microstructural homogeneity is analysed by means of optical light microscopy and scanning electron microscopy. Quantified phase fractions underpin nonequilibrium solidification conditions, when compared to theoretical equilibrium predictions. The assessment of the performed analyses suggests that dual-wire processes are powerful in terms of enhancing achievable depositions rates as well as enabling in situ alloying. This approach might be expandable to multi-wirebased techniques.
\end{abstract}

\section{Introduction}

Wire-arc additive manufacturing (WAAM) is gaining increasing interest due to its manifold prospects for manufacturing medium complex structures with a high deposition rate [1-3]. In this process a metallic wire is fed into an energy source (here the electric arc) resulting in melting of the wire feedstock. The resulting droplet is deposited by a robotic or portal system according to a predefined track cumulatively resulting in the build-up of whole components or the modification of semifinished products [4]. The iterative droplet deposition sequence results in an accumulation of heat - an intrinsic process characteristic - determining the alloy dependent microstructure formation sequence [5-8].

To increase the deposition rate and, more importantly, enable the creation of new, or locally differing alloy composition, feeding two or more wires into the electric arc is desirable as has been suggested for welding with consumable [9-11] and non-consumable electrodes $[12,13]$. However, achieving high quality material properties requires sufficient intermixing of the different alloys via adaption of processing parameters. Here we report on the chemical and microstructural characteristics obtained by in situ alloying Al-Si alloys after the initial process optimisation steps.

In this study we use the well-known Al-Si alloy system as a model system to qualify a dual-wire process based on the cold metal transfer (CMT) welding technology.
Emphasis is placed on the effects triggered using differing chemical compositions of the feedstock wires to form a novel alloy during WAAM by in situ alloying and the resultant effects on microstructure.

\section{Materials and experimental methods}

Commercial aluminium welding wires, ML-AlSi7Mg and ML-AlSi12, were used with $1.2 \mathrm{~mm}$ diameter supplied by MIGAL.CO GmbH with the chemical composition given in Table 1.

The welded material was characterized using chemical analysis by optical emission spectroscopy (OES) (SPECTROMAXx 6 from SPECTRO Analytical Instruments). All compositional values are given in mass percent in this work. The resulting microstructures were analysed by optical light microscopy (OLM) (Olympus BX60) on metallographic specimens. Hardness measurements according to Vickers using a $100 \mathrm{~g}$ load were conducted to assess the effects of microstructural homogeneity on mechanical properties. Moreover, microstructural details were visualised by scanning electron microscopy (SEM) (Tescan Mira 3) at an acceleration voltage of $20 \mathrm{kV}$ using back-scattered electron (BSE) mode. Local chemical compositions were analysed by energy dispersive X-ray spectroscopy (EDX) (EDAX Octane Elect) using an acceleration voltage of $20 \mathrm{kV}$. Additionally, phase fractions were

Corresponding author: thomas.klein@ait.ac.at 
calculated using Thermo-Calc software in combination with the TTA18 database using the global minimization of the Gibbs free energy.

\section{Processing}

The CMT twin system (Fronius $\mathrm{GmbH}$ ) visualised in Fig. 1 was used for the investigations. This setup combines two CMT-systems. Recent works provided evidence for the suitability of CMT for WAAM of various aluminium alloys [8,14-16]. The two torches (ML-AlSi7Mg and ML-AlSi12) were used with mean welding currents of $51 \mathrm{~A}$ and $65 \mathrm{~A}$ and mean voltages of 11.7 $\mathrm{V}$ and $15.9 \mathrm{~V}$, respectively. The travel speed amounted to $5 \mathrm{~mm} / \mathrm{s}$ and the wire feed rates were 3.5 $\mathrm{m} / \mathrm{min}$ each. The CMT twin system was combined with an ABB IRB 4600 welding robot and an ABB IRB 500A workpiece positioner. For the present investigations Argon 5.0 (Linde Gas $\mathrm{GmbH}$ ) was used.

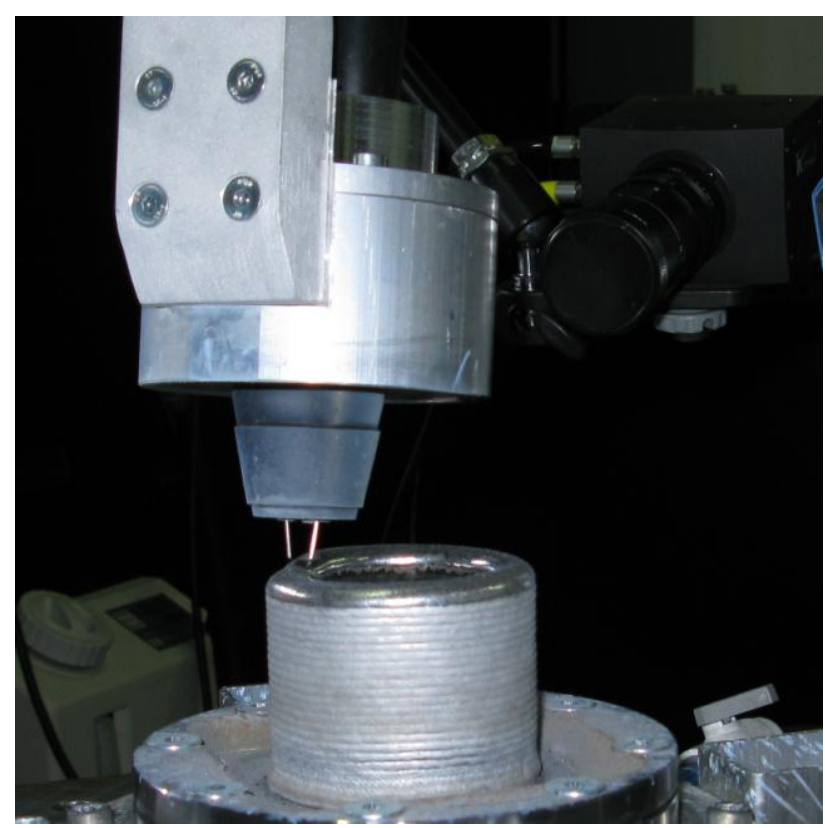

Fig. 1. Dual-wire welding system with parallel wire feeding used in the present study inclusive welded cylindrical specimen on circular flat substrate.

Cylindrical specimens with a diameter of $\approx 70 \mathrm{~mm}$, a height of $\approx 60 \mathrm{~mm}$ and a wall thickness of $\approx 10 \mathrm{~mm}$ were welded on flat substrates as visible in Fig. 1. The target composition was chosen as AlSi10Mg with a composition as given in Table 1. This composition is an exemplary alloy composition, which is not available as commercial welding wire. The detailed analyses of the subsequent subchapters were conducted using the process variant with the apparently best chemical and microstructural homogeneity as well as least porosity, which was obtained by parallel wire feeding (see Fig. 1) and utilization of an oscillating motion.

\section{Material characterisation}

\subsection{Analysis of chemical composition}

Cylindrical structures were welded and cut vertically providing a cross-section suitable for further analyses (schematically shown as inset in Fig. 2(a)). Across this section the chemical compositions were determined at three different heights: Bottom, middle, and top. In Fig. 2 the chemical profiles for the elements $\mathrm{Al}$ (a), Si and $\mathrm{Mg}(\mathrm{b})$ are shown. Alloying elements and impurities with comparably low concentrations are omitted for clarity. Observed variations in all three elements can be identified corresponding to one another. The chemical analyses suggest good chemical homogeneity throughout the specimen in both thickness and height directions. However, the Si target value was not reached and is slightly beneath an acceptable value [17], which could be adjusted by increasing the wire feed rate of the MLAlSi12 welding wire but the actual concentration is not of relevance for the subsequent microstructural analyses.

\subsection{Microstructure and hardness analysis}

A representative OLM micrograph is depicted in Fig. 3 as hardly any microstructural variations were discernible at this scale. Clearly, the primary dendritic solidification is discernible with fairly homogeneously distributed eutectic constituents in the interdendritic regions.

Table 1. Chemical compositions of the welding wires used in the present work as well as the targeted final material composition. All values are given in mass percent.

\begin{tabular}{|c|c|c|c|c|c|c|c|c|}
\hline & Al & Si & $\mathbf{F e}$ & $\mathbf{C u}$ & $\mathbf{M n}$ & $\mathbf{M g}$ & $\mathbf{Z n}$ & $\mathbf{T i}$ \\
\hline ML-AISi7Mg & 91.7 & 7.0 & 0.2 & 0.05 & 0.1 & 0.65 & 0.1 & 0.2 \\
\hline ML-AISi12 & 86.5 & 12.0 & 0.6 & 0.3 & 0.15 & 0.1 & 0.2 & 0.15 \\
\hline Target & 88.5 & 10.0 & 0.44 & 0.20 & 0.13 & 0.31 & 0.16 & 0.17 \\
\hline
\end{tabular}




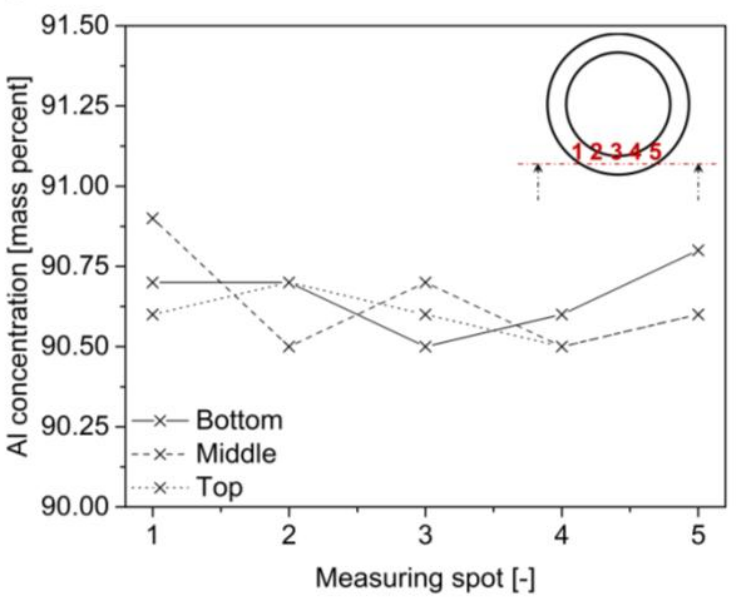

b

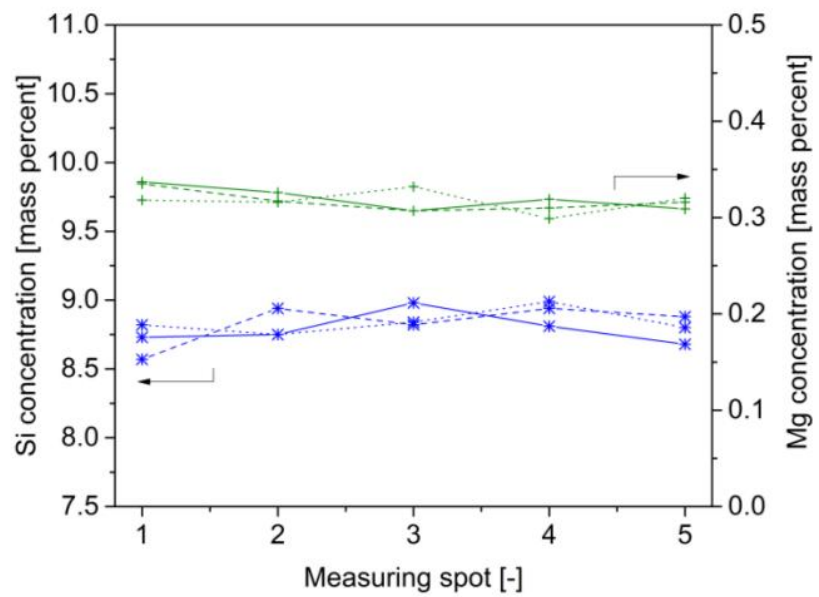

Fig. 2. Variation of chemical composition of the major alloying elements $\mathrm{Al}(\mathrm{a}), \mathrm{Si}$ and $\mathrm{Mg}$ (b). The cross-section prepared for chemical analysis is schematically visualised as inset in Fig. 2(a).

Additionally, some porosity is visible. Porosities in WAAM of aluminium are mainly caused by (i) insufficient shielding gas protection of the melt, (ii) differing hydrogen solubility of liquid and solid aluminium and (iii) insufficient liquid feeding upon solidification. Addressing (i) can be conducted by modification of the shielding gas flow, (ii) by increasing the melt and, thus, feedstock quality and (iii) by variation of WAAM parameters affecting solidification conditions or alloy design targeting grain refinement. In the present work insufficient inert gas shielding of the melt pool was identified as the major cause of porosities. Best results were obtained using a modified shielding gas nozzle as visible in Fig. 1, which may, however, be further improved.

The secondary dendrite arm spacing is in the range of $\approx$ $10 \mu \mathrm{m}$ irrespective of the location within the specimen. According to Refs. [18,19] this magnitude suggests a cooling rate of $\approx 50 \mathrm{~K} / \mathrm{s}$ during solidification in qualitative agreement with Ref. [5].

It is noted that the amount of eutectic constituent appears to be affected by the non-equilibrium solidification, i.e. by the high process-intrinsic cooling rates, dominating the solidification conditions during WAAM. ThermoCalc calculations were performed for the mean actual chemical composition as determined by OES, which is assumed to correspond the microstructure as exemplarily visible in Fig. 3 due to its high homogeneity. It is further assumed that the phase fractions within the eutectic constituent are separated into $\alpha-\mathrm{Al}$ and $\mathrm{Si}$ according to equilibrium condition, which appears reasonable, since eutectic reactions often prevail similarly as in thermodynamic equilibrium due the physical nature of this reaction. These calculations suggest an amount of primary $\alpha$-Al grains of $\approx 32.2$ mole percent in thermodynamic equilibrium at room temperature. Experimentally, this low amount of primary dendrites and corresponding high value of eutectic constituent is not observed in the WAAM processed specimen visualized in Fig. 3. This is unlikely to be due to chemical discrepancies (see Fig. 2). It is argued that the high solidification rate results in a non-equilibrium distribution of $\mathrm{Si}$ and the concomitant variation in the amounts of primary phases. These discrepancies might be equilibrated upon ensuing heat treatments.

Hardness values were measured at the bottom, middle and top section of the specimen. In these three regions values of $80 \pm 3,76 \pm 3$ and $79 \pm 1 \mathrm{HV} 0.1$, respectively, were determined. The slightly higher hardness in the close vicinity of the substrate is presumably due to an increased cooling rate in this specimen region.

\subsection{Microstructure and phase formation}

The microstructure visualized by SEM in BSE mode is depicted in Fig. 4 separated in three different specimen regions (bottom $(a, d)$, middle $(b, e)$, top $(c, f)$ ). Its general appearance is independent of the building direction. The microstructure with regard to primary dendrites and eutectic constituent reflects observations by OLM. Visually the microstructure is comparable to the microstructures reported in Refs. [20,21], which were fabricated by single wire WAAM but differs significantly from microstructures observed after selective laser melting (SLM) [22].The microstructures obtained after SLM are dominated by the severe nonequilibrium condition of the feedstock alloy powders and the subsequent intrinsic heat treatment being repetitive in nature, but due to the particularly small melt pool, cooling rates are much higher than during WAAM.

EDX analysis was used for the identification of additional constituents visible in Fig. 4. Clearly, at the specimen's top fewer bright interdendritic phases are present. In all specimen regions, these phases were identified to be rich in $\mathrm{Al}, \mathrm{Fe}$ and $\mathrm{Si}$ and formed abundantly upon solidification [23]. However, $\mathrm{Mg}$ enrichments are discernible at the bottom and the middle sections in these phases or their close vicinity but were not present at the top. The presence of $\mathrm{Mg}$ containing intermetallic phases in conditions close to equilibrium 
fits well to theoretic predictions based on Thermo-Calc. Thus, it is concluded that the intrinsic heat treatment prevailing during WAAM provides sufficient thermal energy for diffusion resulting in the local accumulation of $\mathrm{Mg}$. Hence, the specimen's top corresponding to a specimen condition far off equilibrium is free of these accumulations. Similar enrichments were detected in Ref. [19] during single wire CMT of an ML-AlSi7Mg0.6 alloy but were not discussed in this work.

\section{Summary and outlook}

In this work the feasibility of in situ alloying of aluminium-based alloys is proven. To this end, two aluminium wires with significantly varying $\mathrm{Si}$ content were used to obtain AlSil0Mg material during dualwire-arc additive manufacturing. From the performed analyses the following major conclusions can be drawn:

-Process optimization enables good chemical homogeneity throughout the cross-section of the welded structures suggesting sufficient intermixing of the two feedstock materials.

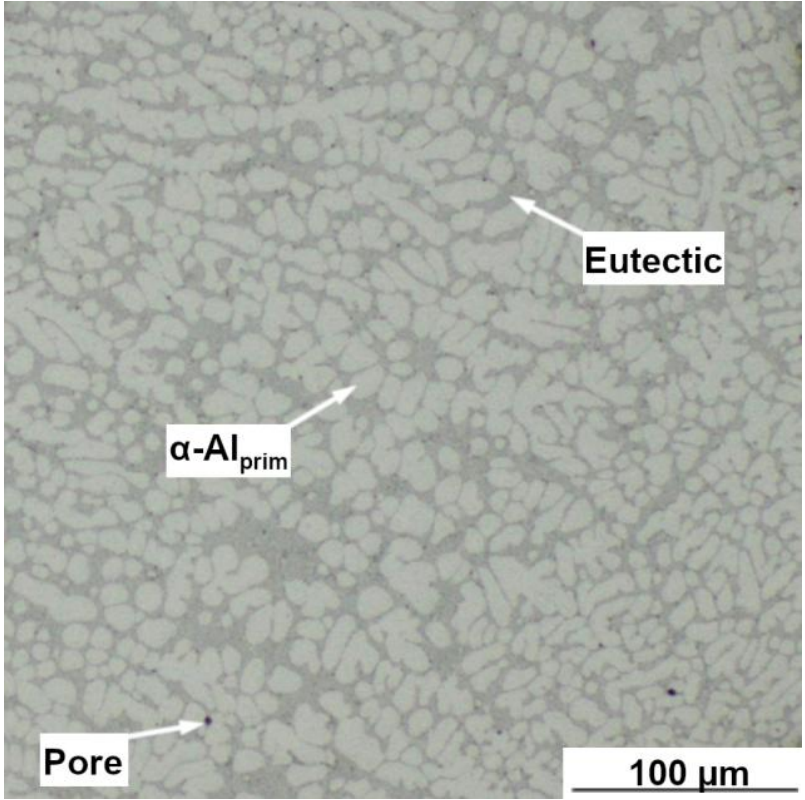

Fig. 3. Representative optical micrograph visualizing primary dendrites with the eutectic constituent in the interdendritic regions as well as small pores.
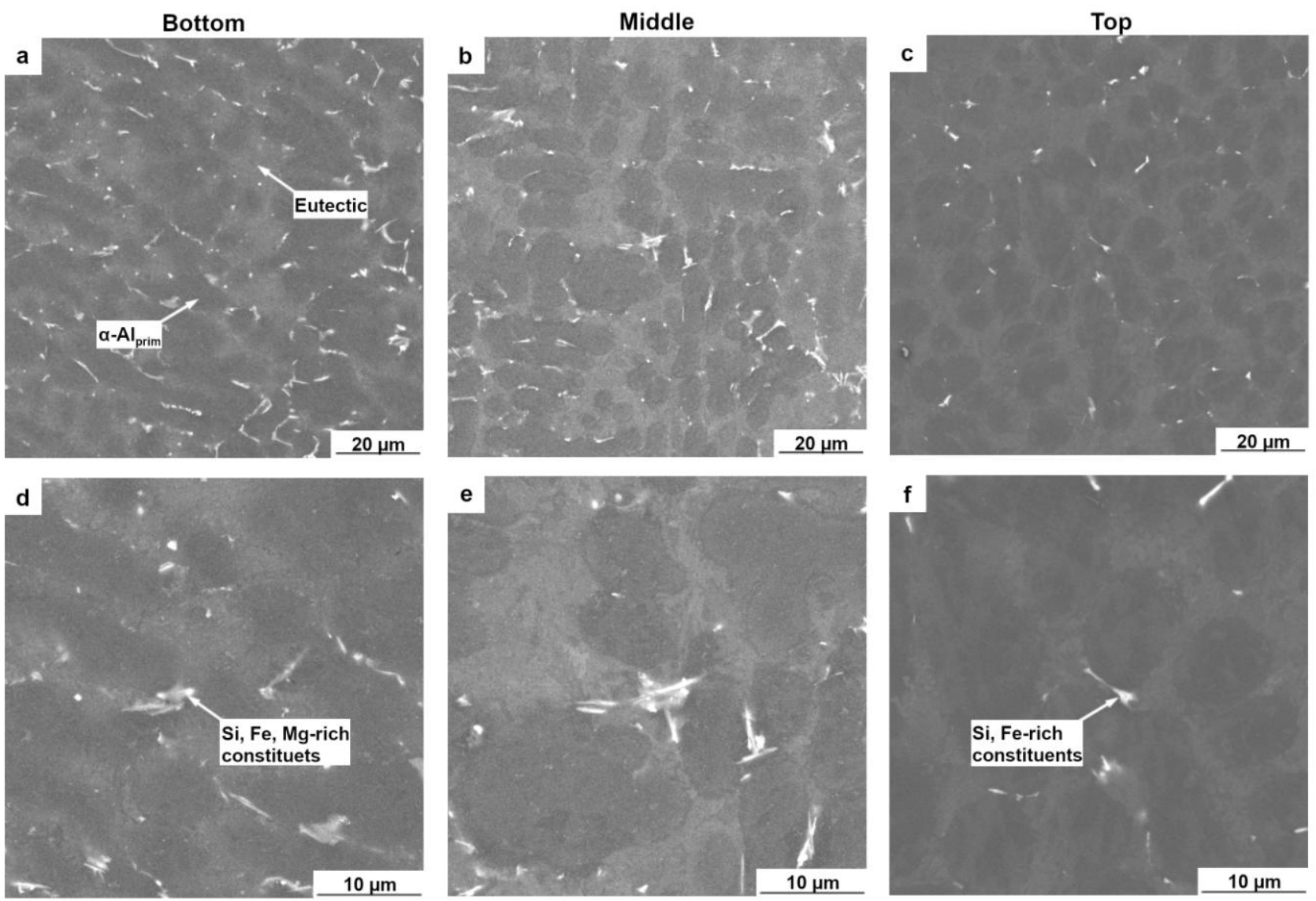

Fig. 4. Micrographs (SEM) taken from the specimen regions bottom (a, d), middle (b, e) and top (c, f). Primary grain and eutectic constituent morphology are similar in all regions. Fewer interdendritic intermetallic phases are visible at the specimen's top. 
-The resultant microstructure is characterized by a fine-grained dendritic appearance resulting from the high cooling rates during solidification.

- Eutectic microstructural constituents appear uniformly distributed within the specimen material.

- Phase fractions observed experimentally deviate from equilibrium predictions resulting from pronounced non-equilibrium solidification conditions.

-SEM analysis provided evidence that the repeated heating results in varying microstructures from bottom to top. Particularly, it is apparent that fewer intermetallic phases are visible at the specimen's top, which is subject to the least heat input.

- EDX analysis shows that in all regions of the specimens, $\mathrm{Al}+\mathrm{Fe}+\mathrm{Si}$-rich phases are discernible. However, the intrinsic heat treatment prevailing during processing results in the accumulation of $\mathrm{Mg}$ in their close vicinity. This phenomenon is proven by the absence of these $\mathrm{Mg}$ enrichments at the specimen's top.

The good homogeneity of the obtained specimen in terms of chemical composition and microstructures suggests that dual-wire approaches in WAAM are feasible and that the approach might be expandable to multi-wire techniques.

This research was funded by the Austrian Federal Ministry for Digital and Economic Affairs (BMDW) within the framework of the program "COIN (Cooperation \& Innovation)" administered by the Austrian Research Promotion Agency (FFG) within the project "PAmelA" (grant no. 872667).

\section{References}

1. D. Ding, Z. Pan, D. Cuiuri, H. Li, Int. J. Adv. Manuf. Technol. 81, 465 (2015)

2. B. Wu, Z. Pan, D. Ding, D. Cuiuri, H. Li, J. Xu, J. Norrish, J. Manuf. Proc. 35, 127 (2018)

3. C.R. Cunningham, J.M. Flynn, A. Shokrani, V. Dhokia, S.T. Newman, Add. Manuf. 22, 672 (2018)

4. H. Lockett, J. Ding, S. Williams, F. Martina, J. Eng. Des. 28 (7-9), 568 (2017)

5. W. Ou, T. Mukherjee, G.L. Knapp, Y. Wie, T. DebRoy, Int. J. Heat Mass Trans. 1271084 (2018)

6. F. Hejripour, D.T. Valentine, D.K. Aidun, Int. J. Heat Mass Trans. 125, 471 (2018)

7. K. Oyama, S. Diplas, M. M'hamdi, A.E. Gunnaes, A.S. Azar, Add. Manuf. 26, 180 (2019)

8. T. Klein, M. Schnall, Int. J. Adv. Manuf. Techn. 108, 235 (2020)

9. J. Gu, J. Bai, J. Ding, S. Williams, L. Wang, K. Liu, J. Mater. Proc. Techn. 262, 210 (2018)

10. F. Martina, J. Ding, S. Williams, A. Caballero, G. Pardal, L. Quintino, Add. Manuf. 25, 545 (2019)

11. Y. Wang, X. Chen, S. Konovalov, C. Su, A. Noor Siddiquee, N. Gangil, Appl. Surf. Sci. 487, 1366 (2019)
12. Z. Qi, B. Cong, B. Qi, H. Sun, G. Zhao, J. Ding, J. Mater. Proc. Techn. 255, 347 (2018)

13. A.E. Davis, C.I. Breheny, J. Fellowes, U. Nwankpa, F. Martina, J. Ding, T. Machry, P.B. Prangnell, Mater. Sci. Eng. A 765, 138289 (2019)

14. X. Fang, L. Zhang, G. Chen, X. Dang, K. Huang, L. Wang, B. Lu, Materials 11, 2075 (2018)

15. J.S. Panchagnula, S. Simhambhatla, Robot Comput. Integr. Manuf. 46, 193 (2018)

16. A. Horgar, F. Fostervoll, B. Nyhus, X. Ren, M. Eriksson, O.M. Akselsen, J. Mater. Proc. Techn. 259, 68 (2018)

17. Schüle Metallgiesserei, Technisches Merkblatt: Legierungen nach DIN EN 1706

18. W. Kurz, D.J. Fisher, Fundamentals of solidification, $4^{\text {th }}$ ed., Trans Tech Publications (1998)

19. A. Furtado Ferreira, J.A. de Castro, L. de Olivé Ferreira, Mater. Res. 20, 68 (2017)

20. Q. Yang, C. Xia, Y. Deng, X. Li, H. Wang, Materials 12, 2525 (2019)

21. C. Li, H. Gu, W. Wang, S. Wang, L. Ren, Z. Wang, Z. Ming, Y. Zhai, Appl. Sci. 10, 70 (2020)

22. J. Wu, X.Q. Wang, W. Wang, M.M. Attallah, M.H. Loretto, Acta Mater. 117, 311 (2016)

23. A. Dinsdale, C. Fang, Z. Que, Z. Fan, JOM 71, 1731 (2019) 